\title{
O ensino de sociologia e a organização do trabalho didático no Colégio Pedro II (1925-1945)
}

\author{
Silvia Helena Andrade de Brito*
}

\begin{abstract}
Resumo:
Este artigo tem como objeto o ensino de sociologia no Colégio Pedro II, entre 1925 e 1945. Seu objetivo é explicitar como se entrelaçam uma dada organização do trabalho didático e o ensino de sociologia, considerando a relação educativa e os instrumentos de trabalho utilizados para o ensino dessa disciplina. Suas fontes primárias são as atas da Congregação; programas de ensino e textos escolares de sociologia. Concluindo, as análises realizadas permitiram mostrar a relação educativa estabelecida no ensino dessa disciplina no Pedro II, mediada ainda pela presença de compêndios. Isto revelou o papel de autores como Delgado de Carvalho, que tiveram influência na difusão do conhecimento sociológico, ou seja, na mediação entre um dado corpus teórico e os professores e alunos do ensino secundário.
\end{abstract}

\section{Palavras-chave:}

organização do trabalho didático; Colégio Pedro II; ensino de sociologia; manuais didáticos; Delgado de Carvalho.

Doutora em Filosofia e História da Educação, participa do Grupo de Estudos e Pesquisas "História, sociedade e educação no Brasil" (HISTEDBR/GT MS) e Grupo de Estudos e Pesquisas "Sociedade, História e Educação" (GEPSE/UEMS). Universidade Federal de Mato Grosso do Sul (UFMS). 


\title{
The teaching of sociology and the organization of the didactic work at Colégio Pedro II School (1925-1945)
}

\author{
Silvia Helena Andrade de Brito
}

\begin{abstract}
:
The object of this paper is the teaching of sociology at 'Colégio Pedro II' School between 1925 and 1945. It aims to clarify how a particular organization of the didactic work is interlinked with the teaching of sociology, considering the discussion about the educational relationship and the textbooks. The primary sources are the Congregation's records, the curricula and the compendium produced for this school subject. In conclusion, the analyses showed the educational relationship established in the teaching of sociology at 'Colégio Pedro II' School, mediated by the presence of textbooks. This revealed the role played by authors such as Delgado de Carvalho, who influenced the dissemination of the sociological knowledge, i.e., in the mediation between a given theoretical corpus and secondary school teachers and students.
\end{abstract}

Keywords:

organization of the didactic work; 'Colégio Pedro II'School; teaching of sociology; textbooks; Delgado de Carvalho. 


\section{Introdução}

Desde sua criação, na primeira metade do século XIX, o então Imperial Colégio de Pedro II já havia sido pensado como escola modelar ${ }^{1}$ para o ensino secundário no país (GASPARELLO, 2004; VECHIA; LORENZ, 1998). Tal projeto consolidou-se nos decênios seguintes, atravessando a Primeira República e se fazendo presente até 1951, quando uma última reforma curricular, emanada da congregação do Colégio Pedro II e aprovada pelo Ministério da Educação e Saúde, teve validade para o ensino secundário público em todo o país (VECHIA; LORENZ, 1998). Foi dentro desse período que houve, na referida escola secundária, a introdução da disciplina sociologia, a qual esteve presente no currículo entre 1925 e a primeira metade dos anos 1940. Em função disso, este também é o marco temporal do presente artigo, parte de um projeto coletivo ${ }^{2}$ que versa sobre os textos escolares utilizados em quatro disciplinas ministradas na referida instituição de ensino, entre elas a sociologia.

1 Sobre este aspecto, duas considerações devem ser feitas. A referência ao Colégio Pedro II baseia-se no entendimento acerca de sua importância para o estudo de como se deram as transformações relativas à organização do trabalho didático no ensino secundário no Brasil, considerando a primeira metade do século XX. Em outras palavras, essa instituição é tomada como lócus de investigação na medida em que representa, no referido momento histórico, a forma mais desenvolvida desse processo (VECHIA; CAVAZOTTI, 2003). Isso não significa, no entanto, deixar-se de reconhecer as especificidades do processo de institucionalização do ensino secundário nas diversas regiões do país, incluindo-se aí a trajetória de distintas instituições escolares. Essa questão, embora não seja priorizada nesse trabalho, vem sendo objeto da historiografia da educação produzida no Brasil. Cf., nesse sentido, a título de exemplo, os trabalhos de Barros (2000), Viana (2004), Vechia (2006), Dallabrida e Carminatti (2007), Dias (2008), Souza (2008), Ranzi e Silva (2009) e Pessanha e Gatti Junior (2012), entre outros.

2 Trata-se do projeto $O$ manual didático como instrumento de trabalho nas escolas secundária e normal (1835-1945), que foi financiado pelo CNPq e contou com os seguintes pesquisadores: Silvia Helena Andrade de Brito, coordenadora do projeto e docente da Universidade Federal de Mato Grosso do Sul; Gilberto Luiz Alves, docente da Universidade Anhanguera-Uniderp; Ana Aparecida Arguelho de Sousa, Carla Villamaina Centeno, Samira Saad Pulchério Lancilloti, João Mianutti, Paulo Edyr Bueno de Camargo e Enilda Fernandes, docentes da Universidade Estadual de Mato Grosso do Sul, todos membros do Grupo de Estudos e Pesquisas "História, Sociedade e Educação no Brasil" (HISTEDBR/GT MS). 
Nesse sentido, este artigo tem como objeto o ensino de sociologia no Colégio Pedro II, entre 1925 e 1945. Seu objetivo geral é explicitar como se entrelaçam uma dada organização do trabalho didático e o ensino de sociologia, na referida instituição de ensino secundário. Entre seus objetivos específicos, arrolam-se a discussão da relação educativa; os recursos didáticos, sobretudo o texto escolar; e o espaço físico, utilizados no ensino dessa disciplina. Para tal, foram coligidas as fontes documentais pertinentes (sobretudo as atas da congregação do Colégio Pedro II e compêndios produzidos por autores como Delgado de Carvalho, catedrático da disciplina durante a maior parte do período aqui considerado; os programas de ensino para a disciplina e a legislação pertinente ao ensino secundário nesse momento histórico); além das obras secundárias sobre a temática em questão.

A partir destes objetivos, o trabalho será dividido em três seções. A primeira terá como preocupação discutir os antecedentes da proposta para implantar a sociologia como disciplina no ensino secundário, que se reporta aos anos iniciais da República, com a reforma Benjamin Constant, de 1890. Se tal proposta não veio a termo, entre outros motivos, pela morte de seu propositor, não passou despercebida no Colégio Pedro II, tendo gerado um interessante debate acerca do caráter e do papel a serem assumidos pela nova disciplina.

A segunda parte deste artigo tem como foco o processo que trouxe a disciplina sociologia para o ensino secundário no Pedro II, a partir de 1925, com a reforma João Luiz Alves/Rocha Vaz, reconstituindo o debate ali travado em torno de sua materialização. Isso envolveu discutir seus programas; a atuação dos professores responsáveis pela disciplina, sobretudo aquele que a conduziu na maior parte deste período, como já destacado, Delgado de Carvalho; os compêndios utilizados, entre outros aspectos. Enfatiza-se aqui que este foi um período de transição para o processo de institucionalização da disciplina sociologia no Brasil, visto que a constituição dos cursos universitários na área de ciências sociais coincidiu com a retirada desta disciplina do currículo do ensino secundário.

Finalmente, na última seção, serão apresentadas as considerações finais acerca deste trabalho. 


\section{Reflexões sobre a categoria organização do trabalho didático e os antecedentes da implantação da disciplina sociologia no Colégio Pedro II}

Como dito anteriormente e inclusive expresso em seu título, a proposta desta análise reporta-se à forma como se encontrava a organização do trabalho didático no Colégio Pedro II, quando em seu currículo foi introduzida a disciplina sociologia. Para tal, serão referidos aqui os resultados de duas pesquisas que se aprofundaram no estudo do trabalho didático e sua organização (ALVES, 2001; 2005). A primeira discutiu a origem e o desenvolvimento da escola moderna. Considerou, em especial, que a organização do trabalho didático dominante nas escolas de nosso tempo se reporta a Comenius e se expressa como uma forma de manifestação da organização técnica do trabalho manufatureiro (ALVES, 2001). A segunda tinha como objetivo fundamental evidenciar as diversas formas históricas de organização do trabalho didático que se sucederam, desde a emergência do ensino de caráter coletivo, ainda na sociedade feudal, com o modus parisiensis de ensinar, em meados do século XVI, até o predomínio do ensino mútuo no século XIX. Foi no interior desse segundo trabalho que Alves começou por explicitar claramente a acepção conferida à categoria organização do trabalho didático:

a) ela é, sempre, uma relação educativa que coloca, frente a frente, uma forma histórica de educador, de um lado, e uma forma histórica de educando(s), de outro;

b) realiza-se com a mediação de recursos didáticos, envolvendo os procedimentos técnico-pedagógicos do educador, as tecnologias educacionais e os conteúdos programados para servir ao processo de transmissão do conhecimento;

c) e implica um espaço físico com características peculiares, onde ocorre. (ALVES, 2005, p. 10-11, grifo do autor).

Serão estes os três elementos, portanto, a serem considerados para a presente análise acerca do Colégio Pedro II e da disciplina sociologia. O exame destes elementos, no entanto, se baseará em três pressupostos. O primeiro abrange o fato de que, contrariamente ao esperado numa leitura mais apressada 
da temática em estudo, ao se tratar da organização do trabalho didático no Colégio Pedro II, está-se considerando essa instituição educativa não de per si, mas como parte de um movimento mais amplo, que se apresenta como uma tendência própria ao processo de desenvolvimento da escola moderna no Brasil, particularmente da secundária.

O segundo pressuposto é que a mesma tendência se apresenta como chave explicativa quando se observa não apenas a disciplina sociologia, mas o conjunto dos conteúdos que ali se materializam. Ao mesmo tempo, contudo, e este é o terceiro pressuposto, busca-se entender as particularidades da organização do trabalho didático no ensino secundário e em especial no Colégio Pedro II, bem como o desenvolvimento específico da disciplina sociologia no seu interior.

Nestes termos, considera-se que o ensino secundário no Brasil, desde o final do século XIX, vivia um momento de transição, que se estenderia até o final da primeira metade do século seguinte. Esta transição contrapunha dois modelos de ensino secundário: um que, nas palavras de Haidar (2008, p. 240), estava “[...] destinado por seu caráter geral e desinteressado a formar e robustecer o espírito da juventude sem orientá-lo diretamente para qualquer especialização futura, [e] continuava, pois, exclusivamente incumbido de preparar para os cursos superiores [...]”, o que permanecia como herança do período imperial; e um segundo que, ainda mantendo caráter geral, segundo a mesma autora, pautar-se-ia pelo ensino eminentemente científico, um dos traços distintivos da escolarização na modernidade.

Examinada esta transição, no que respeita à organização do trabalho didático, pode-se considerar que ainda não se realizara no ensino secundário no Brasil, até os meados do século XX, aquelas que seriam as marcas predominantes da escola moderna.

Voltando à proposta de Alves (2005) para caracterizar a organização do trabalho didático na escola moderna, a relação educativa nele presente implica a existência de um dado tipo de educando, o aluno - na verdade, um coletivo de alunos - por um lado, e um dado educador - o professor - por outro. Esta nova realidade, proposta por Comenius, tornou necessária a divisão dos estudos por séries, bem como a elaboração de programas e planos de estudos especializados, a fim de atender aos níveis de escolarização propostos. $\mathrm{Ou}$ seja, implicava a definição de fronteiras disciplinares e de um profissional afeito a esta nova demanda - o professor - também ele em vias de tornar-se um especialista. Envolvia igualmente a especialização dos instrumentos de 
trabalho, no caso, manuais didáticos, agora múltiplos, pois ajustados a cada nível de escolarização e a cada área do conhecimento ${ }^{3}$.

Ora, este processo não se completará no Colégio Pedro II e, por que não, em todo o ensino secundário no Brasil antes que se torne imperativo, frente à necessidade de expansão do ensino público neste grau da escolarização, o que se efetivará tão somente na segunda metade do século XX. Antes deste momento histórico, a formação de classes ou mesmo a sua frequência foram objeto ora de maior, ora de menor fiscalização por parte do poder público. Exemplos disto podem ser encontrados na própria legislação republicana para o ensino secundário: na Reforma Benjamin Constant, de 1891 (VIEIRA, 2008) ainda estava presente a possibilidade de o educando preparar-se para os exames finais do secundário fora do Pedro II ou colégios equiparados. Já o Código Epitácio Pessoa, de 1901, como lembra Saviani (2007, p. 170), “[...] pôs fim à liberdade de freqüência [...]”, embora mantendo a equiparação das escolas privadas às escolas oficiais. Ainda segundo o mesmo autor, e demonstrando o processo de transição que marcou este momento histórico:

Mas a reforma Rivadávia Correa, em 1911, volta a reforçar a liberdade de ensino e a desoficialização. Diante das conseqüências desastrosas, uma nova reforma, a de Carlos Maximiliano, instituída em 1915, reoficializou o ensino e introduziu o exame vestibular a ser realizado nas próprias faculdades, podendo a ele se submeter apenas os candidatos que dispusessem de diploma de conclusão de curso secundário [...] (SAVIANI, 2007, p. 170).

No mesmo sentido, a ata da congregação do Colégio Pedro II, de 28 de junho de 1893, também relatava a existência de alunos ouvintes na instituição, que se preparavam para exames avulsos (COLÉGIO..., 1891-1899), situação que permaneceu sem solução definitiva até os anos 1930 (ROMANELLI, 1978). A formação de um coletivo homogêneo de alunos, relacionados a uma dada série escolar, requisito essencial para que se implantasse a relação

3 "A cada classe sejam destinados livros de texto próprios, que contenham todo o programa prescrito para essa classe (quanto à instrução, à moral e à piedade), para que, durante o espaço de tempo em que os jovens são conduzidos pelo caminho destes estudos, não tenham necessidade de nenhum outro livro, e com a ajuda destes livros possam ser conduzidos infalìvelmente às metas fixadas [...]" (COMÉNIO, 1976, p. 430). 
educativa própria à escola moderna, foi fruto de um processo paulatino no ensino secundário, cujas etapas mais decisivas se darão, em termos legais, a partir de 1925, com a Reforma João Luiz Alves/Rocha Vaz, já no alvorecer de transformações próprias à nova etapa de desenvolvimento da sociedade capitalista no Brasil, e que se fortalecerão nas décadas de 1930 e 1940. Acompanhando este processo, foi paulatina também a constituição de um espaço físico adequado ao novo contexto, embora o ensino secundário no Pedro II tenha contado, desde muito cedo, com instalações destinadas exclusivamente às atividades ali praticadas - embora não houvessem sido edificadas para este fim - situação pouco frequente em escolas situadas fora da capital da República (CUNHA JUNIOR, 2008) ${ }^{4}$.

Conforme assinalado anteriormente, o trabalho didático também se organiza, no entanto, na presença de um conjunto de elementos necessários à mediação no interior da relação educativa. Destes elementos fazem parte os recursos didáticos - sobressaindo-se, no contexto da escola moderna, $\mathrm{o}$ manual didático -, além dos procedimentos técnico-pedagógicos do professor, as tecnologias educacionais e os conteúdos dos diferentes programas de ensino (ALVES, 2005).

Cabe aqui, para tratar-se dos referidos elementos, um novo voltar de olhos para Comenius. Preocupado com a organização do trabalho didático ${ }^{5}$, este educador procurou fundamentalmente definir o que tornaria possível a realização da nova relação educativa, um instrumento de trabalho que, aperfeiçoado pelo próprio Comenius, passaria a ser o elemento preponderante no trabalho didático, pois a ele caberia a função de garantir a transmissão do conhecimento. Visto dessa perspectiva, o manual didático, instrumento

4 Excede os limites deste trabalho a possibilidade de discutir aspectos mais pontuais do espaço físico do Colégio Pedro II, como os gabinetes montados para o ensino de determinadas disciplinas, como a física ou a química; a existência de salas de aula especialmente destinadas para o desenvolvimento das disciplinas, como aquela voltada à geografia, e que se encontra até o presente momento preservada na unidade central da instituição, antiga sede do externato, no período histórico aqui tratado.

5 Vale lembrar que "[...] na direção da argumentação desenvolvida, a organização do trabalho didático é uma categoria subordinada, desde o momento em que é produzida no campo da educação. [...] A organização do trabalho didático constitui-se, conceitualmente, nos limites de outras categorias mais centrais, tais como trabalho e organização técnica do trabalho, e as implica [...]" (ALVES, 2005, p. 10, grifo do autor). 
de trabalho por excelência dentro da escola moderna, portanto, não teve um surgimento casual e aleatório. Ele foi o recurso intencionalmente vislumbrado por Comenius para o exercício da função aventada. Assistia-se, assim, à emergência da supremacia do instrumento de trabalho no âmbito da educação escolar, criando-se os pressupostos para a instauração do domínio da atividade do professor pelo manual didático (ALVES, 2001).

Continuando esta discussão, Alves enfatiza como pode surpreender o fato de o manual didático ter-se cristalizado e ganho uma longa sobrevida, mesmo em face da ocorrência da revolução industrial e da emergência de outros instrumentos de trabalho didático. Sua presença longeva na relação educativa é significativa, visto ser o manual didático um recurso cujo surgimento é datado historicamente, nascido e pensado por Comenius como um elemento importante no século XVII, visando atender às necessidades educacionais de então. A escola do manual didático, contudo, embora tenha continuado com as suas bases plantadas no século XVII e, portanto, preservando a organização manufatureira do trabalho didático, tornou-se cada vez mais presente nos séculos seguintes. Nesse processo histórico, o manual didático, que pretendia oferecer uma síntese dos conhecimentos humanos, mais adequada ao trabalho do professor com crianças e jovens,

Especializou-se, também, em função dos níveis de escolarização e das áreas de conhecimento, multiplicando-se da mesma forma que os instrumentos de trabalho, dentro da oficina, que, por força da divisão do trabalho, ganharam as configurações mais adequadas às operações que realizavam. Desde então, o manual didático passou a servir em tempo integral ao aluno e ao professor. Foram criadas, mesmo, modalidades especializadas de textos para aquele e para este, mas, rigorosamente, concebidas como elementos complementares. De imediato, importa reconhecer que o manual didático, pela sua auto-suficiência enquanto instrumento organizador do trabalho de ensino dispensou da escola outros elementos, como o livro clássico [...] (ALVES, 2001, p. 86-87).

Em outras palavras, o manual didático, nos moldes propostos por Comenius, marca uma tendência própria à escola moderna, qual seja, a simplificação e objetivação do trabalho didático. Tal como ocorrera com o trabalho em geral, na sociedade capitalista, era necessário que o trabalho didático fosse simplificado e objetivado, permitindo a qualquer homem o 
exercício do magistério, até então função restrita a homens de saber inaudito . $^{6}$ Nesta direção, o manual didático, ao longo de sua trajetória histórica, por um lado, foi progressivamente ampliando a simplificação dos conteúdos a serem transmitidos ao aluno. Com isso, e cada vez mais, "[...] a transmissão do conhecimento, na escola, identificou-se, de fato, com a sua vulgarização [...]” (ALVES, 2005, p. 71, grifo nosso). Por outro, tornou desnecessária a utilização de outros recursos didáticos, como o texto clássico ${ }^{7}$. Ainda na vereda do processo de especialização do saber científico e da seriação, imprimiu a mesma organização ao trabalho didático.

Ora, no momento de transição, que está posto em termos de ensino secundário no Brasil entre o final do século XIX e a primeira metade do século $\mathrm{XX}$, ainda não se coloca claramente a hegemonia do manual didático, como o texto escolar predominante na organização do trabalho didático. Entre os determinantes deste processo, aponta-se a própria expansão e universalização deste grau de ensino, que ainda não se colocara em toda a sua extensão no horizonte da sociedade capitalista no Brasil, neste momento histórico. Da mesma forma, o processo de especialização dos níveis de escolarização não se completara no país, uma vez que o ensino superior, sobretudo no campo das humanidades, ainda demandava a implantação das universidades, o que se fará apenas nos anos 1930.

Assim, examinados em seu conjunto, os procedimentos técnico-pedagógicos do professor, as tecnologias educacionais e os conteúdos dos diferentes programas de ensino, condizentes com os compêndios utilizados, até meados das primeiras décadas do século XX, particularmente no Colégio Pedro II, ilustram o patamar em que se encontrava a organização do trabalho didático

6 Tal relação, de caráter individual, elevava significativamente os custos dos serviços educacionais, pois o preceptor deveria ser um “[...] artífice primoroso [...]” e “[...] dotado de conhecimentos invulgares [...]” (ERASMO, 1996, p. 9; 26), isto é, um sábio cujo conhecimento elevava-se muito acima da média.

7 Toma-se obra clássica neste texto na seguinte acepção: "Clássicas são aquelas obras de literatura, de filosofia, de política que permaneceram no tempo e continuam sendo buscadas como fonte de conhecimento. E continuarão desempenhando essa função pelo fato de terem registrado, com riqueza de minúcias e muita inspiração, as contradições históricas de seu tempo, elas são produções ideológicas, pois estreitamente ligadas às classes sociais e aos interesses que delas emanam, mas são também meios privilegiados e indispensáveis para que o homem reconstitua a trajetória humana e descubra o caráter histórico de todas as coisas que produz [...]" (ALVES, 1993, p. 21). 
no ensino secundário no Brasil. Alguns exemplos ilustram essa assertiva. Quanto aos compêndios - cuja denominação já indica, na verdade, não se tratarem dos manuais comenianos em sua forma mais desenvolvida - remetase ao trabalho de Alves e Centeno (2009), ao analisarem os livros voltados ao ensino de história do Brasil, no Pedro II, entre o final do século XIX e começo do século XX. Assim:

Se consideradas as prescrições de Comenius, as características imanentes aos quatro textos referidos são pouco compatíveis com as do manual didático da escola moderna. São textos extensos, envolvendo lições com nível informativo detalhado e denso, o que termina por conferir um alentado volume aos livros ${ }^{8}$. Mesmo o de Macedo, a despeito de comportar questionários e quadros sinóticos, não escapa dessa consideração. $\mathrm{O}$ de Bellegarde desenvolve-se ao longo de 260 páginas. O de Abreu e Lima inclui dois volumes, com 324 e 200 páginas, respectivamente. O manual de Macedo contém 519 páginas, enquanto o de Mattoso Maia, 346. Outra característica que os distancia dos modernos manuais didáticos comenianos é a despreocupação com as ilustrações. Todos os livros relacionados não as exploram ao longo das lições ou dos capítulos que os integram (ALVES; CENTENO, 2009, p. 474).

Em relação aos procedimentos técnico-pedagógicos do professor, os autores explicitam que a concepção de trabalho didático destes professores, calcada na centralidade do papel do magister, também contribuía para reforçar a visão sobre o papel desse profissional na relação educativa. Esse aspecto contrasta com o domínio crescente que será exercido, posteriormente, pelo manual didático sobre o professor.

8 Por ordem alfabética, trata-se das seguintes obras: BELLEGARDE, Henrique Luís de Niemeyer. Resumo de Historia do Brasil até 1828. Traduzido de Mr. Denis, correcto e augmentado por H. L. de Niemeyer Bellegarde. Rio de Janeiro: Typ. Gueffier, 1831; LIMA, José Ignacio de Abreu e. Compendio de historia do Brasil. 2 t. Rio de Janeiro: Eduardo \& Henrique Laemmert, 1843; LIMA, José Ignacio de Abreu e. Synopsis ou deducção chronologica dos fatos mais notaveis da historia do Brasil. Pernambuco: Typographia de M. F. de Faria, 1845; MACEDO, Joaquim Manoel de. Lições de historia do Brasil para uso das escolas de instrucção primaria. Rio de Janeiro/Paris: Livraria Garnier, 1913; MAIA, Luis de Queirós Mattoso. Lições de historia do Brazil. Rio de Janeiro: B. L. Garnier, 1886. 
Outras indicações quanto aos procedimentos a serem adotados pelos professores, embora presentes em documento que sumariza as instruções para o exercício do magistério no período imperial para as aulas de retórica (1863), fazem recomendações que Alves e Centeno (2009) também encontraram nos compêndios de história do Brasil, utilizados entre o final do século XIX e começo do XX. Entre elas, destaca-se a complementação das lições dos compêndios com outros textos, inclusive com o uso de obras clássicas, contrária à recomendação comeniana, que indicava o manual didático como único texto a ser utilizado por professores e alunos:

As lições de Rhetorica são acompanhadas de textos de todos os autores nacionaes, portuguezes, e de outras nações, originaes ou traduzidos, e especialmente da lingua latina, e nas lições de Portugues e de Litteratura nacional são os alumnos obrigados a escrever breves composições nos differentes generos da arte [...] (COLÉGIO..., 1863, p. 5).

Assim, pode-se afirmar que, nesse contexto, as fontes clássicas ainda eram utilizadas no ensino ministrado no Colégio Pedro II. Além disso, é importante lembrar que, no referido período histórico, esses professores tinham a autoria dos compêndios utilizados, frente ao fato de que eram, em larga medida, detentores do conhecimento ali exposto. Isto também os diferenciará do momento histórico em que, por força da expansão da escola pública, em seus diversos níveis, o mercado editorial imporá outra divisão do trabalho na confecção do manual didático, aparecendo a figura do escritor de textos escolares - manuais didáticos - persona distante e separada daquele que será tão somente um de seus consumidores habituais, o professor (SOUZA, 2010).

Feitas essas ponderações, o que dizer, no entanto, do conhecimento científico, como era o caso da sociologia, dado o caráter particular do ensino secundário voltado para a formação do bacharel em ciências e letras?

A discussão acerca dos programas de ensino no secundário e do lugar nele ocupado pelo conhecimento científico, em especial pela sociologia, revela uma especificidade própria a este momento de transição no Colégio Pedro II, naquele período denominado Ginásio Nacional. Estas disputas ficaram mais evidenciadas entre 1890 e 1892, ocasião em que foi discutida e operacionalizada a Reforma Benjamin Constant (decreto n. 981, de 8 de novembro de 1890 (VIEIRA, 2008). Em ata lavrada a 27 de março de 1896, a congregação recordava que, entre 1890 e 1892, os programas foram uma 
combinação daquele aprovado pela Reforma Benjamin Constant e os antigos planos de ensino, anteriores a 1890, cujo retorno fora autorizado pelo então Ministro da Instrução Pública, João Barbalho Uchôa Cavalcanti, sucessor de Constant (COLÉGIO..., 1891-1899; DÓRIA, 1997). Desta forma, o programa de 1892 ainda se inspiraria na Reforma Benjamin Constant, conforme consta, inclusive, de sua epígrafe (VECHIA; LORENZ, 1998).

Tal inspiração, contudo, era parcial. Indo ao encontro desta afirmação, constata-se que a disciplina sociologia, proposta pela legislação de 1890 , não foi implantada no colégio neste momento histórico, e, por isto, também não figura no rol disciplinar de 1892. Isso denota o debate então travado, que envolvia tanto o processo de especialização do conhecimento científico, ainda inconcluso, sobretudo no campo das ciências humanas, ainda mais quando o ensino secundário assumia o lugar de formação superior no campo das humanidades; como a forte rejeição, evidenciada na discussão contra o positivismo, e seu caráter cientificista. Exemplo disso pode ser encontrado em disputa ocorrida na reunião da Congregação do Pedro II, em 2 de julho de 1892, quando contrapõem-se, por um lado, Rodolpho de Paula Lopes, catedrático de história natural, e por outro Sylvio Romero, catedrático de filosofia (COLÉGIO..., 1891-1899).

Paula Lopes defendia a cadeira de sociologia e moral, proposta pela Reforma Constant, considerando-a mais de acordo com a verdadeira questão filosófica - dada como resolvida pelo positivismo, quando se contrapõe à metafísica - e simultaneamente combatendo a identificação da sociologia com alguma seita religiosa (Apostolado Positivista), como declarado pelos seus adversários. Reafirmava o caráter científico da sociologia, um aspecto ainda pouco entendido da reforma proposta por Constant, segundo o mesmo Paula Lopes, dada a recepção ainda precária do positivismo.

Romero rebatia apresentando três argumentos:

O primeiro, explicando que, desde 1880, vinha defendendo a inserção do ensino de sociologia no currículo do ensino secundário, baseado num plano simplificado de ensino, construído a partir da obra de Herbert Spencer. Disto resultara a seguinte proposta: "Primeiros principios, principios de psycologia, principios de sociologia e principios de moral [...]" (COLÉGIO..., 1891-1899, p. 17). Esclarece que esta última, no entanto, nunca fora aprovada pela Congregação; 
Ao mesmo tempo, e este era o segundo argumento, acreditava ser necessário que se mantivesse a disciplina lógica formal e real no $6^{\circ}$ ano. Romero esclarece que, na Reforma Constant, o plano de ensino de sociologia e moral foi proposto para o lugar da filosofia ${ }^{9}$. Lembra que, em verdade, para o positivismo, os únicos princípios lógicos que tinham validade eram aqueles derivados do fazer científico. Disso resultaria, para os positivistas, não ser pertinente a existência de uma disciplina ocupada especialmente com essa discussão, que já estaria se realizando ao serem discutidos os princípios metódicos das ciências especializadas presentes no currículo;

O terceiro argumento era a defesa da manutenção dos estudos sociológicos com a disciplina história das civilizações, que teria como conteúdo fundamental discutir os aspectos comuns - sociológicos, portanto - presentes na evolução de todas as civilizações (COLÉGIO..., 1891-1899).

Resulta deste debate que, conforme anunciado por Sylvio Romero, no programa de 1892 os pontos de sociologia foram agregados à disciplina história das civilizações. O professor Manoel de Gouvêa declarava, na mesma ocasião, em nome da comissão que elaborou a proposta de reformulação dos planos de ensino de Benjamin Constant, que a disciplina sociologia havia sido retirada para não incitar um espírito religioso, ou o combate à Igreja (COLÉGIO..., 1891-1899).

Percebe-se assim, na discussão em torno dos programas de filosofia e da disciplina sociologia e moral, questões que seriam resolvidas quando se completasse o processo de especialização do conhecimento científico no campo das humanidades, dando ensejo: à institucionalização da sociologia enquanto disciplina científica, e a concomitante formação dos cursos superiores nessa área, com seu desligamento da filosofia, a partir dos anos 1930 (MEUCCI, 2000); e a redução do caráter enciclopédico da cadeira de filosofia, com seu estreitamento ao estudo da lógica, outra faceta do processo de especialização do conhecimento próprio a este momento de transição (CUSTÓDIO, 2011). Isso também esteve relacionado ao surgimento de cursos superiores em outras áreas das humanidades, além da sociologia, como foi o caso da psicologia (ANTUNES, 2003; 2008).

9 E, segundo Romero, foi-lhe também atribuído, pela congregação do Ginásio Nacional, seu desenvolvimento (COLÉGIO..., 1891-1899). 


\section{A implantação e implementação da disciplina sociologia no Colégio Pedro II}

Passado este momento de efervescência em torno da sociologia - mais precisamente, um indício de críticas dirigidas à Reforma Constant e, particularmente, à sua base positivista, na qual a sociologia tinha lugar de destaque - os debates em torno de sua implantação e implementação no ensino secundário só voltaram a acontecer na segunda metade dos anos 1920.

Vivia-se, neste momento histórico, o "[...] clima de ebulição social característico da década de 1920 [...]" (SAVIANI, 2007, p. 193), que fez emergir, no campo educacional, o movimento escolanovista, ancorado no processo de urbanização pelo qual passava o país, resultante do avanço da industrialização, sobretudo na região sudeste do Brasil. Prenúncio deste novo horizonte, a última reforma da Primeira República, conhecida como João Luiz Alves/Rocha Vaz (VIEIRA, 2008), já citada anteriormente, reforçou os mecanismos de controle do Estado sobre o ensino secundário, tendência que já estivera presente na legislação anterior - a Reforma Carlos Maximiliano - e que seria a marca da atuação estatal, no pós-1930. Assim,

A implantação generalizada de um ensino ginasial, seriado e com freqüência obrigatória, e o alargamento das funções normativas e fiscalizadoras da União quanto à instrução secundária de todo o país constituíram aspectos fundamentais desta nova lei de ensino [...] (NAGLE, 2001, p. 194).

Neste sentido, generalizou-se o regime seriado, que até então constituía uma exceção no ensino secundário, por um lado. Por outro, tanto os exames de preparatórios como os parcelados foram abolidos para aqueles alunos que não estivessem matriculados em escolas equiparadas, nas unidades federativas ou no Colégio Pedro II (NAGLE, 2001).

Na nova seriação proposta pelo decreto $16.782 \mathrm{~A}$, de 13 de janeiro de 1925, em seu artigo $47^{\circ}$, aparecia a disciplina sociologia, no sexto e último ano do ensino secundário. Ainda, segundo Nagle (2001, p. 197), 
A presença da sociologia, no currículo, constitui inovação muito significativa. [...] [Assim,] a década de 1920, no domínio do "pensamento brasileiro", caracterizou-se pela forte impregnação de preocupações de natureza "sociológica". No mesmo sentido deve ser interpretada a inclusão da sociologia nos estudos secundários [...]. A utilização e o desenvolvimento do pensamento social, na década, foram cada vez maiores nos meios intelectuais, entre jornalistas, escritores, políticos ou estudiosos. Por isso, nesse período, a sociologia poderia ser considerada a "arte de salvar rapidamente o Brasil", de acordo com a afirmação de Mário de Andrade.

Some-se a este clima, o caráter científico que o movimento renovador entendia como necessário para que se realizassem as transformações requeridas pela educação no Brasil, que redundou na defesa do estreitamento dos laços entre a educação e as ciências sociais. Isso reforçava, indo ao encontro do exposto acima por Nagle, a existência de um ambiente propício à implantação e implementação da disciplina sociologia no ensino secundário. Nesta direção, a ata da congregação do Colégio Pedro II, de 28 de agosto de 1925 (COLÉGIO..., 1920-1925) sugeria o nome de Adrien Delpech ${ }^{10}$ para ocupar a recém-criada cadeira de sociologia, visto que o tema do concurso do referido professor para a cátedra de filosofia versara sobre "A logica da sociologia".

$\mathrm{Na}$ condição de primeiro professor de sociologia do Colégio Pedro II, Adrien Delpech foi, provavelmente, o responsável pelo programa que abriu o ensino da disciplina, aprovado em reunião da congregação em 29 de abril de 1926 (COLÉGIO..., 1925-1934). A permanência de Delpech deveu-se ao fato de que ainda não havia concurso previsto para a cadeira de sociologia naquele ano, quando também haveria a instalação do $6^{\circ}$ ano, conforme previsto na Reforma João Luiz Alves/Rocha Vaz (VIEIRA, 2008) ${ }^{11}$. Logo, visando à continuidade da disciplina no novo ano letivo, a congregação deveria indicar

10 "O professor Adrien Delpech era belga, nascido no ano de 1867. Fez seus estudos de todos os níveis em Paris. No ano de 1825, aos 25 anos de idade, chegou ao Brasil, onde se estabeleceu definitivamente. No Rio de Janeiro ingressou no Colégio Pedro II, em seguida no Instituto de Educação e na Escola Nacional de Música, lecionando Francês e Artes. [...] Foi professor de várias disciplinas, inclusive Literatura Brasileira, pela qual nutria especial predileção [...]" (SOARES, 2009, p. 86).

11 Com a Reforma Carlos Maximiliano, de 1915, o ensino secundário fora organizado em cinco anos, medida revogada pela Reforma João Luiz Alves/Rocha Vaz, em 1925, que promoveu o retorno do $6^{\circ}$ ano ao ensino secundário (VIEIRA, 2008). 
novamente um professor interino, com a escolha recaindo sobre o mesmo Delpech. Também, nesta reunião, foram aprovados em bloco os programas para as disciplinas do sexto ano, inclusive o de sociologia, com o professor Delpech indicando os livros a serem utilizados na referida disciplina.

A mesma situação repetiu-se nos anos de 1927 e 1928, quando o programa da disciplina, sem as discussões que repetidas vezes apareceram na aprovação de outras matérias, como foi o caso da filosofia, foi aprovado, respectivamente, em 26 e 27 de março dos referidos anos (SOARES, 2009, p. 91). Somente em 1929 apareceria um novo programa, quando a disciplina sociologia já estava sob a direção do catedrático Carlos Delgado de Carvalho ${ }^{12}$, que assumira a cadeira em substituição a Adrien Delpech, em 21 de novembro de 1927 (DÓRIA, p. 234-235) ${ }^{13}$. Delgado de Carvalho permaneceu na condição de catedrático da disciplina até 1941, quando a sociologia passou à condição de disciplina optativa no ensino secundário.

Neste ínterim, após a Revolução de 1930, duas reformas foram impostas ao ensino secundário: a primeira, em 1931, que ficou conhecida pelo nome do então ocupante do recém-criado Ministério da Educação e Saúde, Francisco Campos; e a segunda, em 1942, também referida pelo nome do então ocupante do ministério, Gustavo Capanema. Em 1931, um dos principais problemas ainda enfrentados pelo ensino secundário estava na sua definição como etapa intermediária para as escolas superiores, o que fortalecia a permanência dos exames parcelados e do sistema de preparatórios, apesar dos esforços da Reforma João Luiz Alves/Rocha Vaz, de 1925. Na perspectiva de maior centralização e constituição de um sistema nacional de ensino, o decreto $n$.

12 Dada a sua importância para o ensino de sociologia no Colégio Pedro II, será feita menção especial a Delgado de Carvalho em momento posterior do texto.

13 Não consta, no livro de atas da congregação do Colégio Pedro II relativo ao ano de 1927, menção a uma reunião daquele colegiado na data indicada por Escragnolle Dória (1997). Seria necessário, assim, confrontar tal informação com outros documentos, como os livros de nomeações da instituição. Dois indícios, contudo, podem servir, temporariamente, para corroborar a informação de Dória. Primeiro, na data em que foi nomeado para a cadeira de sociologia, Delgado de Carvalho, provavelmente seguindo a tradição do Pedro II, não modificou de imediato o programa da disciplina, mantendo-o para o ano de 1928. No ano de 1929, no entanto, novo programa foi firmado (VECHIA; LORENZ, 1998), e este já contou, provavelmente, com a participação do novo catedrático da disciplina, sendo este o segundo indício a ratificar a afirmação de Escragnolle Dória. 
19.890, de 18 de abril de 1931, consolidado pelo decreto n. 21.241, de 4 de abril de 1932, insistiu sobre a organicidade do ensino secundário, com base nos seguintes princípios: currículo seriado; frequência obrigatória; organização em dois ciclos, um fundamental, de 5 anos, “[...] obrigatório para o ingresso em qualquer escola superior e o segundo [complementar, de 2 anos, obrigatório para o ingresso] em determinadas escolas [...]”(ROMANELLI, 1978, p. 135); equiparação de todos os colégios secundários públicos e privados ao Pedro II, mediante inspeção federal; concurso para o corpo docente, com seu registro junto ao ministério. Nesta nova estrutura, a sociologia aparecia no segundo ano do ciclo complementar, nos cursos voltados para os candidatos que se dirigiam às Faculdades de Direito, Medicina, Odontologia e Farmácia, e Engenharia e Arquitetura.

A Reforma Capanema, de outra feita, mantendo os princípios básicos da Reforma Francisco Campos, reestruturou a escola secundária, criando um primeiro ciclo, o ginasial, com quatro anos de duração, e um segundo ciclo, o colegial, com três anos, que se subdividia em científico e clássico (ROMANELLI, 1978, p. 159). A disciplina sociologia permaneceu obrigatória apenas nas escolas normais, embora pudesse ser acrescentada ao currículo da escola secundária, na condição de disciplina optativa (CARVALHO, 2004).

Em relação à organização do trabalho didático, neste período que vai de 1925 a 1941, embora ainda se esteja transitando para o que viria a ser o trabalho didático mais próximo àquele pensado por Comenius para a escola moderna, pode-se, entretanto, evidenciar particularidades que diferenciam esse momento do anteriormente analisado.

No que tange à relação educativa, é interessante chamar a atenção para a expansão do ensino médio em todo o país, o que certamente vai determinar que a organização do trabalho didático se volte em direção ao ensino coletivo, consagrado pelas diretrizes educacionais voltadas para o fortalecimento da seriação e todo seu corolário no campo curricular. Destaque-se ainda que o ensino médio abrangia, além do secundário, todo o ensino profissional, que também fora alvo das reformas secundadas por Francisco Campo e Gustavo Capanema. Ensinos secundário e profissional, juntos, passaram de 109.421 matriculados em 1920, para 557.434 matrículas em 1950 (ROMANELLI, 1978, p. 64, 77).

Ora, para fazer frente a esta demanda crescente pelo ensino médio, que mais que quintuplicou as matrículas entre 1920 e 1950, era mister organizar o 
ensino coletivo, tornando presente a proposta comeniana tanto para a escola secundária como para a profissional.

Neste sentido, a relação educativa necessária ao ensino coletivo também se fez presente no Colégio Pedro II que, paulatinamente, segundo informações presentes em seus documentos oficiais, foi alvo, da mesma forma, deste vertiginoso crescimento no número de matrículas. Em ata da congregação de 13 de abril de 1927 (COLÉGIO..., 1925-1934), relatava-se o atendimento de cerca de 1.300 estudantes na instituição, entre alunos do internato e externato.

Ainda caminhando na mesma direção, “[...] o número de turmas do Externato aumenta de 28 em 1932, para 37 em 1933, o que implicou um aumento de 490 alunos [...]" (COLÉGIO..., 1925-1934, p. 53). Esta tendência de aumento da demanda no ensino secundário, significando para o Colégio Pedro II um número crescente de inscritos para seu concurso de acesso, levou a instituição, já na década de 1950, a ampliar o número de vagas, bem como o espaço físico para suas instalações, com a inauguração das seções norte e sul (1952) e da seção Tijuca (1957) ${ }^{14}$.

Diante das novas características impostas para a relação educativa pelo processo de expansão do ensino secundário, importa neste momento caracterizar os outros elementos presentes na organização do trabalho didático, necessários à mediação no interior da relação educativa. São eles, como afirmado anteriormente, os recursos didáticos (ALVES, 2005) - sobressaindose, no contexto da escola moderna, o texto escolar - além dos procedimentos técnico-pedagógicos do professor, as tecnologias educacionais e os conteúdos dos diferentes programas de ensino.

Dada sua importância, uma vez que permaneceu na cátedra de sociologia no Pedro II, por pelo menos 13 dos dezesseis anos em que a disciplina esteve presente na grade curricular da instituição, cabe aqui uma menção mais detalhada a Carlos Delgado de Carvalho, autor de compêndios de sociologia ${ }^{15}$ destinados tanto ao ensino secundário, naquela que era a escola de referência

14 As seções do Colégio Pedro II, até 1957, eram: a seção centro, primeira edificação própria do colégio e sede do externato (atual Unidade Educacional (U.E.) Centro); a seção São Cristovão, sede do internato (atual U.E. São Cristóvão); a seção norte (atual U.E. Engenho Novo); a seção sul (atual U.E. Humaitá) e a seção Tijuca (atual U.E. Tijuca) (COLÉGIO..., 2011).

15 A obra de Delgado de Carvalho, produzida entre 1910 e 1975, inclui volumes com fins didáticos e para a formação de professores em vários campos disciplinares, entre eles, além da Sociologia, a Geografia, a História, a Didática, entre outros (COSTA, 2006). 
para esse grau de ensino - o Colégio Pedro II -, como também ao ensino normal e ao Instituto de Educação (COSTA, 2006; 2007; MEUCCI, 2000), entre os anos 1920 e 1950. Compartilha com outros autores, como Fernando de Azevedo, um papel importante no momento de consolidação da sociologia como disciplina escolar no ensino secundário, motivo que determinou a forte produção de textos escolares, sobretudo entre os anos 1930-1940, destinados à escola secundária brasileira. Distintamente de Azevedo, contudo, esse autor teve uma sintonia estreita com parcelas da intelligentsia carioca ainda representativa dos meandros da Primeira República, como o Instituto Histórico e Geográfico Brasileiro. Além disso, seu avô, José Dias Delgado de Carvalho havia sido professor do Imperial Colégio de Pedro II. Foi no Instituto Histórico e Geográfico Brasileiro que iniciou também sua carreira de escritor, com o volume Geographia do Brasil, de 1913, seu primeiro livro escrito em português que, embora não tenha sido produzido para fins didáticos, ganhou notoriedade nessa condição (COSTA, 2006).

A produção de Delgado de Carvalho na área de sociologia inclui oito volumes: Sociologia (1931); Sociologia educacional (1933); Sociologia e educação (1934); Sociologia experimental (1934); Práticas de sociologia (1939); Didática das ciências sociais (1949); Textos de sociologia educacional (1951); e Introdução metodológica aos estudos sociais (1957) (SOARES, 2009). Visando a trazer elementos para a análise da organização do trabalho didático no Colégio Pedro II, foram utilizados para o exame particularmente os manuais Sociologia, de 1931; Sociologia experimental, de 1934 e Práticas de sociologia, de 1939.

Inicialmente, é importante destacar que a produção deste autor na área de sociologia veio a termo, sobretudo, quando de seu entrelaçamento com o movimento escolanovista ${ }^{16}$, visto que se colocou como tarefa não só a divulgação da visão da Escola Nova acerca da sociologia, mas, também, a de enfatizar o caráter prático dessa ciência, num momento considerado como de reconstrução da vida nacional. Assim,

16 Delgado de Carvalho foi signatário do "Manifesto dos Pioneiros da Educação Nova" de 1932, bem como do "Manifesto dos Educadores mais uma vez convocados", em 1959. Cf. Ghiraldelli Junior (1991). 
O que daí se depreende é que os estudos sociologicos estão ligados a problemas praticos, correspondem a necessidades prementes, encaram situações reais, precisam de dados, de fatos, de informações exatas para auxiliar planos de reconstrução e de reajustamento num futuro proximo [...] (CARVALHO, 1934, p. 10).

Com essa preocupação, seus trabalhos dirigiram-se a professores e alunos com o intuito, por um lado, de demonstrar as bases científicas do pensamento sociológico e, por outro, de usar este conhecimento para entender e atuar na realidade social do país, isto é, "[...] produzir novos processos de explicação e novas interpretações de fenômenos [...]" (COSTA, 2006, p. 3392), fundamentalmente por meio dos inquéritos e da pesquisa social.

Disso resultaria a necessidade de simplificação e objetivação do trabalho didático, por meio de seu instrumento, o texto escolar ${ }^{17}$ : “[...] o compêndio visa, por conseguinte, adaptar-se ao alumno menos adiantado [...]" (CARVALHO, 1929 apud COSTA, 2006, p. 3392). Em outras palavras, embora tendo como base o trabalho ativo, pressupondo um aluno que seria encaminhado para a atuação criativa frente à escola, Costa reconhece, ao tratar de um texto escolar de história produzido pelo autor nesse período, que, uma vez dirigidos ao ensino coletivo, nele, necessariamente,

As atividades vão sendo descritas como uma rotina que deveria ser seguida diariamente: exposição sumária do assunto, indicação de duas leituras, exercícios, definição de tópicos a serem estudados, realização de testes, redação de uma carta histórica e uma biografia, indicação da bibliografia e, por fim, apresentar documentos gráficos. (COSTA, 2006, p. 3395, grifo nosso).

Da mesma forma, no texto escolar voltado à sociologia encontram-se todos os materiais necessários a cada uma das etapas previstas no trabalho didático. Veja-se, a título de exemplo, a obra Práticas de sociologia (CARVALHO, 1939), destinada a apresentar a matéria essencial da sociologia, disciplina

17 Não é demais lembrar que neste momento histórico, contudo, a produção material da escola secundária no Brasil, visando atender a uma parcela ainda pouca expressiva da população brasileira, não tornara imperiosa a presença do manual didático, expressão mais acabada do processo de simplificação e objetivação do instrumento de trabalho didático. 
do curso complementar, tendo como objetivo a preparação do aluno para os exames de ingresso nas escolas superiores. Considerando o capítulo 1, "Sociologia, conceito, definição, métodos", o livro segue o plano seguinte, válido para todos os seus treze capítulos: a) sumário, com uma apresentação sucinta do conteúdo da unidade; b) planos de dissertações, englobando modelos de dissertação que poderiam ser objeto dos exames; c) tópicos a discutir, selecionados para uma possível arguição oral; d) notas e documentação, com pequenos extratos de textos selecionados sobre a matéria em questão; e) referências; e f) quando se tratava de matéria inédita, para a qual ainda não havia bibliografia consolidada, acrescentavam-se apêndices do autor.

Quanto ao seu conteúdo, em especial aquele dedicado à apresentação da teoria de Émile Durkheim e Karl Marx, Delgado de Carvalho, determinado pela necessidade da síntese e, simultaneamente, pelo empenho em apresentar, da forma mais ampla possível, os fundamentos da ação prática no campo social - características afeitas aos seus textos, na qualidade de compêndios - estabelece um diálogo entre essas diferentes correntes teóricometodológicas. Sua chave analítica, contudo, não é aquilo que ele denomina como "escola sociológica francesa", mas a sociologia norte-americana ${ }^{18}$.

Assim, o objeto da sociologia seriam "[...] as manifestações determinaveis e exteriores da sociabilidade [...]" (CARVALHO, 1934, p. 15). A partir desse denominador comum, que percebe os fenômenos sociais como exteriores ao homem, como coisas, logo, passíveis de serem conhecidos pela análise sociológica, as singularidades das diversas concepções são igualadas - e simplificadas - em uma condição comum de "particularismos na interpretação sociológica". O que viria se modificando, ao longo da história da explicação sociológica, como já citado anteriormente, seria o que cada autor apresenta como determinante para a análise do fato social, que "[...] se traduz pela hipotese da evolução em Spencer, pelo determinismo econômico de Karl Marx, pela imitação de Gabriel Tarde, pela força social de Lester Ward,

18 Antonio Candido já chamava a atenção, ao discorrer sobre a formação da sociologia no Brasil, para as particularidades da obra de Delgado de Carvalho, cuja produção de material voltado para o ensino e para a divulgação da visão sociológica estaria “[...] orientado pelas teorias americanas e de acentuado intuito prático [...]" (CANDIDO, 2006, p. 284). 
pelas representações coletivas de Durkheim [...]" (CARVALHO, 1934, p. 12, grifo do autor).

Carvalho, portanto, parece considerar Durkheim como uma referênciachave para o desenvolvimento do pensamento sociológico, embora não a única, como deixa claro na introdução de Práticas de sociologia (CARVALHO, 1939). A apresentação da teoria funcionalista está subordinada, contudo, aos objetivos didáticos da exposição, que visa a sumariar a produção existente, apresentando-a de forma simplificada ao leitor, de modo a subsidiar o caráter utilitário da explicação sociológica.

Como visto anteriormente, em termos históricos, Carvalho produziu seus compêndios quando ainda não havia se completado o processo de expansão do ensino secundário público no país, ou seja, a "escola para todos" ainda não se materializara em toda a sua dimensão. Sem ela, a necessidade do manual didático comeniano, bem como o processo de simplificação e objetivação do ensino não atinge sua expressão mais acabada. Assim, o autor reconhece que suas obras, mesmo sendo de caráter introdutório, eram úteis para discentes do ensino superior, o que viria a estender ainda mais a formação desse aluno, por um lado. Por outro, o caráter enciclopédico que marcava os programas do ensino secundário, durante todo este período, faz-se presente, uma vez que ainda torna necessário um compêndio como sociologia (CARVALHO, 1931) que, mesmo simplificado, estendia-se por 280 páginas (primeiro volume), a fim de alcançar todos os pontos previstos no programa da disciplina em 1929.

Contraditoriamente, contudo, Delgado de Carvalho, que já se encontrava mais preocupado com a função utilitária da Sociologia, com a sua divulgação entre o alunado mediano, não intentava produzir um instrumento de trabalho que se preocupasse primordialmente com a erudição dos alunos, sendo esta tarefa adiada para momentos posteriores de sua formação, conforme já afirmado. Demonstrando a tendência à crescente simplificação e objetivação do trabalho didático, e num contexto em que a sociologia ficou limitada ao curso complementar, mais especificamente, às provas para ingresso em cursos superiores, Práticas de sociologia (CARVALHO, 1934), em formato e letras menores, cingia-se, nas palavras do autor, à matéria essencial.

$\mathrm{O}$ viés erudito observado nos compêndios do período anterior, ainda observados por Alves e Centeno (2009) quando tratam de alguns autores do século XIX e início do XX, desta forma, transformam-se, bem como o comprometimento do professor com a utilização de textos clássicos. Tanto no caso de Sociologia (CARVALHO, 1931) como no caso de Práticas 
de sociologia (CARVALHO, 1934), os textos dos manuais efetivamente dispensam o uso dos clássicos, na medida em que resumem para o aluno (e, é claro, também para o professor) o que foi produzido por Durkheim ou outros sociólogos. Esse traço do manual didático, que na proposta comeniana representava a perspectiva de barateamento da atividade de ensino, visto que dispensaria tanto a erudição do professor como tornaria mais acessível o conhecimento assim veiculado (produzindo um livro mais econômico), já está presente na obra de Carvalho. Vai completar-se, no entanto, quando a universalização da escola tornar necessário o surgimento do manual didático, com um custo ainda menor.

Além disso, pode-se afirmar que os compêndios de Carvalho, colocandose mais claramente já na transição entre o texto escolar, antes e durante a expansão da escola secundária, apresentam ainda duas modalidades de materiais: ora assumem um caráter sintético (Práticas de sociologia), ora assumem uma estrutura mais alargada (Sociologia; Sociologia experimental). Também estes últimos, contudo, dispensam a leitura dos clássicos para sua utilização. Mesmo as recomendações de leituras complementares, quando aparecem, não fazem menção a essas obras. Ao contrário, parecem ter o intuito de dispensar o leitor de beber nas fontes clássicas.

Assim, tendo se tornado o elemento que vai direcionar o desenvolvimento do trabalho didático, o texto escolar ganhou espaço no interior da relação educativa. Em função disso, no plano das metodologias de ensino, o autor, por um lado, proclama a importância do professor na tarefa educativa: "É sufficiente um rapido exame do texto para perceber que a palavra do mestre é indispensável ao desenvolvimento e explicação das palavras curtas, quasi telegraphicas que constituem estes summarios." (CARVALHO, 1931, grifo nosso); por outro, dedica parte de seus esforços a esclarecer como melhor utilizar o compêndio. A fala aos professores (VIDAL, 2001 apud COSTA, 2006, p. 3389), ainda num momento de transição, discorre de forma geral sobre como o texto poderia servir de guia no trabalho do professor, embora o autor, preso a uma visão pragmática da sociologia, preocupe-se em pormenorizar as tarefas a serem desenvolvidas pelo docente, tendo como base o texto escolar.

Para finalizar esta exposição, resta destacar os programas que estiveram em vigor para a disciplina, neste período. O primeiro deles, como citado anteriormente, foi aquele produzido por Delpech, e publicado em 1926 (VECHIA; LORENZ, 1998). Ainda condizente com as propostas que balizaram os programas produzidos no período imperial e início do século 
XX, tratava-se de uma extensa sequência de pontos, dividida em duas partes: "Sociologia theorica" e "Fontes historicas da sociologia". A primeira parte, ainda que longa, denotava as preocupações com os temas que, nos trilhos do desenvolvimento teórico naquele momento histórico, poderiam ser caracterizados como propriamente "sociológicos", ou seja, movidos pela perspectiva que vinha iluminando a senda da especialização do conhecimento científico na área. Entre eles, por exemplo, a definição dos limites e métodos da sociologia; a formação das sociedades e a discussão acerca da família; a questão do Estado e a preocupação com o trabalho, propriedade e riqueza, além do debate acerca da evolução do conhecimento dos sistemas sociológicos.

Segundo Soares (2009), contudo, a segunda parte do programa, "Fontes historicas da sociologia", aproximava-se mais propriamente de uma "história das civilizações", mesclando conhecimentos históricos e sociológicos, que buscavam contextualizar o surgimento de diferentes instituições sociais como a família, a cidade, a educação, entre outras. Ou seja, denotava o retorno à proposta que viera se mantendo desde 1890, e que já fora combatida pela Reforma Benjamin Constant, quando esta última propusera como meta especificar a natureza do conhecimento propriamente sociológico. Assim, o programa de 1926 ainda representava uma conciliação entre estas duas tendências.

O programa seguinte, de 1929 (VECHIA; LORENZ, 1998), cujo responsável já seria Delgado de Carvalho, cingia-se a uma proposição baseada numa sociologia entendida enquanto ciência especializada. Abrangia cinco partes, a saber: 1. as teorias sociológicas, sumariando o desenvolvimento histórico da disciplina; 2 . as sociedades, abrangendo os fatores que levaram ao desenvolvimento da vida social; 3. a psicologia social, que incluía aspectos relativos ao papel da cultura na vida social; 4. as instituições, discutindo as características das principais formas de organização presentes na vida social, tais como a família, o Estado, a estrutura econômica das sociedades, entre outras; 5. os problemas sociais contemporâneos, buscando exatamente enfatizar o caráter pragmático do pensamento sociológico, trazendo para o centro do debate científico as questões que preocupavam o homem da sociedade de então. Enfatiza-se ainda que, parte deste programa, encontrase expressa na obra Sociologia, de 1931, de Delgado de Carvalho. Note-se também que o título três, embora referido à psicologia social, enfatiza a questão da cultura, categoria umbilicalmente ligada à tradição das ciências sociais (CUCHE, 2002). 
O último dos programas localizados, quando a sociologia já se encontrava apenas no curso complementar, surgiu num contexto em que os catedráticos do Colégio Pedro II já não eram mais responsáveis pela elaboração dos currículos do ensino secundário, nem mesmo aqueles a serem utilizados na própria escola. Esta atribuição, desde a Reforma Francisco Campos, em 1931, passara a ser da recém-criada Diretoria Geral do Departamento Nacional de Educação, órgão do Ministério de Educação e Saúde (SOARES, 2009, p. 105). Constava o referido programa oficial, na verdade, de uma listagem dos pontos a serem trabalhados visando às provas para o ingresso no curso superior. Condizente com este processo que levou até onde era possível, naquele momento histórico, a objetivação e simplificação do trabalho didático na disciplina sociologia, o programa oficial servia de índice ao respectivo texto escolar de Carvalho (1939, capa), Práticas de sociologia, cujo subtítulo deixava clara sua finalidade: “[...] matéria essencial (circulares 1.200 e 3.344 do D.N.E.) para concurso de habilitação às escolas superiores - 1938 [...]”.

\section{Considerações finais}

Concluindo, enfatiza-se que a hipótese levantada por este trabalho é que o ensino secundário no Brasil, desde o final do século XIX, vivia um momento de transição, que se estenderia durante a primeira metade do século seguinte, abrangendo igualmente a organização do trabalho didático para o ensino de sociologia, no Colégio Pedro II.

No início desta transição, entre a última década do século XIX e o início do século XX, ainda não se colocava claramente nem a relação educativa, pautada pelo ensino coletivo; nem a hegemonia dos procedimentos, das técnicas de ensino, dos currículos ou do instrumento de trabalho que marcariam a escola moderna, com a predominância do uso do manual didático. Entre os determinantes deste processo, que só viriam a se destacar a partir dos anos 1930, apontam-se as próprias transformações econômicas, sociais e políticas em andamento no Brasil, que demandaram a expansão e universalização do ensino secundário, o que ainda não se colocara em toda a sua extensão, no horizonte da sociedade capitalista no país; bem como o processo de especialização dos níveis de escolarização, que não se completara, uma vez 
que o ensino superior, sobretudo no campo das humanidades, ainda demandava a implantação das universidades, o que se fará apenas nos anos seguintes.

Tendo sido criadas as condições acima expostas, transformaram-se a relação educativa, os procedimentos, as técnicas de ensino, os currículos e o principal instrumento de trabalho da escola moderna, o manual didático, ganhou centralidade na relação educativa. Como em outras disciplinas, isso também esteve presente quando da implantação e implementação da disciplina sociologia no Colégio Pedro II, processo iniciado em 1925. Assim, enquanto ganhava espaço, na visão educacional difundida pelo escolanovismo, a importância do pensamento científico, o conhecimento contraditoriamente se afastava da escola, despojada do saber científico no processo que, centrado na simplificação e objetivação do trabalho didático, colocou o manual didático como principal instrumento de trabalho do professor.

\section{Referências}

Alves, Gilberto Luiz. A produção da escola pública contemporânea. Campo Grande: UFMS; Campinas: Autores Associados, 2001.

. O pensamento burguês no Seminário de Olinda (1800-1836). Ibitinga: Humanidades, 1993.

. O trabalho didático na escola moderna: formas históricas. Campinas: Autores Associados, 2005.

Alves, Gilberto Luiz; Centeno, Carla Villamaina. A produção de manuais didáticos de história do Brasil: remontando ao século XIX e início do século XX. Revista Brasileira de Educação, Rio de Janeiro, v. 14, n. 42, p. 469-487, dez. 2009.

Antunes, Mitsuko Aparecida Makino. A psicologia no Brasil: leitura histórica de sua constituição. São Paulo: EDUC; Unimarco, 2003.

. Psicologia Escolar e Educacional: história, compromissos e perspectivas. Psicologia Escolar e Educacional, Campinas, v. 12, n. 2, p. 469-475, jul./dez. 2008.

Barros, Eva Cristini Arruda Câmara. Atheneu Norte-Riograndese: práticas culturais e a formação de uma identidade (1892-1924). 2000. Tese (Doutorado em Educação)-Pontifícia Universidade Católica de São Paulo, São Paulo, 2000. 
Candido, Antonio. A Sociologia no Brasil. Tempo Social, São Paulo, v. 18, n. 1, p. 271-301, jun. 2006.

Carvalho, Carlos Delgado de. Práticas de sociologia. Porto Alegre: Globo, 1939.

. Sociologia: summarios do curso do sexto ano. Rio de Janeiro: Francisco Alves, 1931.

. Sociologia experimental. Rio de Janeiro: Sauer, 1934.

. Introdução. In:

(Org.). Sociologia e ensino em debate: experiências e discussão de Sociologia no ensino médio. Ijuí: EdUnijuí, 2004. p. 17-60.

Colégio Pedro II. Livro de Atas da Congregação do Colégio Pedro II: 1891-1899. Rio de Janeiro, 1891-1899.

. Livro de atas da Congregação do Colégio Pedro II: 1920-1925. Rio de Janeiro, 1920-1925.

. Livro de atas da Congregação do Colégio Pedro II: 1925-1934. Rio de Janeiro, 1925-1934.

- Summario das instrucções que devem ser observadas no ensino das materias do curso de estudos do Imperial Collegio de Pedro II durante o anno lectivo de 1863. Rio de Janeiro: Typ. Nacional, 1863.

. Disponível em: <http://pt.wikipedia.org/wiki/Col\%C3\%A9gio_Pedro_ II>. Acesso em: 07 fev. 2011.

Coménio, João Amós. Didáctica Magna: tratado da arte universal de ensinar tudo a todos. 2. ed. Lisboa: Calouste Gulbekian, 1976.

Costa, Patrícia Coelho. A voz do mestre: trajetória intelectual de Carlos Delgado de Carvalho. 2007. Dissertação (Mestrado em Educação) - Universidade Estadual do Rio de Janeiro, Rio de Janeiro, 2007.

- Uma escrita aos professores: os prefácios dos livros de Delgado de Carvalho. In: Congresso Luso-Brasileiro de História da EducaÇÃo, 6., 2006. Anais... Uberlândia: EdUFU, 2006. p. 3386-3396.

Cuche, Denys. A noção de cultura nas ciências sociais. 2. ed. Bauru: EdUSC, 2002.

Cunha Junior, Carlos Fernando Ferreira da. O Imperial Collegio de Pedro II e o ensino secundário da boa sociedade brasileira. Rio de Janeiro: Apicuri, 2008. 
Custódio, Thiago Oliveira. Escola secundária e filosofia nacional: o Colégio Pedro II entre o ecletismo filosófico e o curso de lógica (1848-1900). 2011. Dissertação (Mestrado em Educação) - Universidade Federal de Mato Grosso do Sul, Campo Grande, 2011.

Dallabrida, Noberto; Carminati, Celso João (Orgs.). O tempo dos ginásios: ensino secundário em Santa Catarina (final do século XIX - meados do século XX). Campinas: Mercado de Letras, 2007.

DiAs, Amália. Apostolado cívico e trabalhadores do ensino: história do magistério do ensino secundário no Brasil (1931-1946). 2008. Dissertação (Mestrado em Educação)-Universidade Federal Fluminense, Niterói, 2008.

DóRIA, Escragnolle. Memória histórica do Colégio de Pedro Segundo (1837-1937). Apresentação de Roberto Bandeira Accioli. Brasília: INEP, 1997.

Erasmo, Desidério. De pueris. Revista Intermeio, Campo Grande, v. 2, n. 3, 1996. Encarte especial.

Gasparello, Arlette Medeiros. Construtores de identidades: a pedagogia da nação nos livros didáticos da escola secundária brasileira. São Paulo: Iglu, 2004.

Ghiraldelli Junior, Paulo. História da educação. São Paulo: Cortez, 1991.

HaIDAR, Maria de Lourdes Mariotto. O ensino secundário no Brasil Império. 2. ed. São Paulo: EdUSP, 2008.

Meucci, Simone. A institucionalização da sociologia no Brasil: os primeiros manuais e cursos. 2000. Dissertação (Mestrado em Sociologia) - Universidade Estadual de Campinas, Campinas, 2000.

Nagle, Jorge. Educação e sociedade na Primeira República. 2. ed. Rio de Janeiro: DP\&A, 2001.

Pessanha, Eurize Caldas; Gatti Junior, Decio (Orgs.). Tempo de cidade, lugar de escola: história, ensino e cultura escolar em escolas exemplares. Uberlândia: EdUFU, 2012.

Ranzi, Serlei Maria Fischer; Silva, Maclovia Corrêa da. Práticas disciplinares inauguradas com a República no ensino secundário paranaense. Pro-Posições, Campinas, v. 20, n. 1, p. 149-171, 2009.

Romanelli, Otaíza de Oliveira. História da educação no Brasil (1930-1973). Petrópolis: Vozes, 1978. 
Saviani, Dermeval. História das idéias pedagógicas no Brasil. Campinas: Autores Associados, 2007.

Soares, Jefferson da Costa. O ensino de Sociologia no Colégio Pedro II (19251941). 2009. Dissertação (Mestrado em Educação) - Faculdade de Educação da Universidade Federal do Rio de Janeiro, Rio de Janeiro, 2009.

SouzA, Ana Aparecida Arguelho de. Manuais didáticos: formas históricas e alternativas de superação. In: Brito, Silvia Helena Andrade de et al. (Orgs.). A organização do trabalho didático na história da educação. Campinas: Autores Associados, 2010. p. 121-145.

SouzA, Rosa Fátima de. História da organização do trabalho escolar e do currículo no século XX (ensino primário e secundário no Brasil). São Paulo: Cortez, 2008.

Vechia, Ariclê. Formando cidadãos e líderes: o ensino secundário na Província do Paraná. Revista HISTEDBR, Campinas, n. 22, p. 54-70, jun. 2006.

Vechia, Ariclê; Cavazotti, Maria Auxiliadora (Orgs.). A escola secundária. São Paulo: Annablume, 2003.

Vechia, Ariclê; Lorenz, Karl Michael (Orgs.). Programa de ensino da escola secundária brasileira (1850-1951). Curitiba: 1998.

Viana, Natércia Micheletti. Belo Horizonte e o Ginásio Mineiro: um projeto de civilização para a mocidade (1898-1914). 2004. Dissertação (Mestrado em Educação)-Universidade Federal de Minas Gerais, Belo Horizonte, 2004.

VIEIRA, Sofia Lerche (Org.). Leis da reforma da educação no Brasil: Império e República. Brasília: INEP, 2008.

Endereço para correspondência: Silvia Helena Andrade de Brito Rua José Antonio Pereira, 1518, apto. 1201 Campo Grande - MS CEP: 79002-930 E-mail: silvia.brito@ufms.br

Recebido em: 28 dez. 2011 Aprovado em: 23 ago. 2012 